\title{
Capítulo 3 - O caso da vacina tríplice e o autismo o que os erros nos ensinam sobre os aspectos da natureza da ciência
}

\author{
Renato Barboza \\ Simone Alves de Assis Martorano
}

\section{SciELO Books / SciELO Livros / SciELO Libros}

BARBOZA, R., and MARTORANO, S.A.A. O caso da vacina tríplice e o autismo: o que os erros nos ensinam sobre os aspectos da natureza da ciência. In: MOURA, B. A., and FORATO, T. C. M., comps. Histórias das ciências, epistemologia, gênero e arte: ensaios para a formação de professores [online]. São Bernardo do Campo, SP: Editora UFABC, 2017, pp. 53-69. ISBN 978-85-68576-84-7. https://doi.org/10.7476/9788568576847.0004.

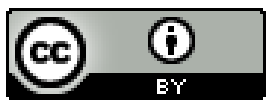

All the contents of this work, except where otherwise noted, is licensed under a Creative Commons Attribution 4.0 International license.

Todo o conteúdo deste trabalho, exceto quando houver ressalva, é publicado sob a licença Creative Commons Atribição $\underline{4.0}$.

Todo el contenido de esta obra, excepto donde se indique lo contrario, está bajo licencia de la licencia $\underline{\text { Creative }}$ Commons Reconocimento 4.0. 


\section{O CASO DA VACINA TRÍPLICE E O AUTISMO: O QUE OS ERROS NOS ENSINAM SOBRE OS ASPECTOS DA NATUREZA DA CIÊNCIA}

Renato Barboza

Simone Alves de Assis Martorano

\section{Introdução}

Pesquisas atuais têm enfatizado a importância da história e filosofia da ciência (HFC) para o ensino e aprendizagem de conceitos científicos (GIL-PÉREZ, 1993; GONZÁLEZ, 1994; CACHAPUZ; PRAIA; JORGE, 2002; NÍAZ, 2009; PORTO, 2010). A história da ciência, por exemplo, ajuda a superar as dificuldades encontradas no entendimento de conceitos científicos. Nesse sentido, Porto (2010) mostra que o estudo e discussão de episódios históricos podem propiciar aos estudantes a superação de visões inadequadas sobre a natureza do conhecimento científico, por exemplo, a ideia de que existe um único "método científico".

Embora existam importantes motivos e justificativas para a inclusão da história e filosofia da ciência no ensino, Níaz (2009) aponta que, devido à complexidade da natureza da ciência, mesmo para filósofos da ciência, algumas das controvérsias entre os pesquisadores na área de ensino de ciências estão 
centradas na questão do que deve ser incluído e em que nível de complexidade. Deve-se, portanto, levar em consideração quais ideias sobre a ciência o professor espera que seus alunos construam e, também, se está preparado para abordar esse tema em suas aulas.

Segundo Níaz (2009), apesar de controvérsias, certo grau de consenso foi alcançado dentro da comunidade de pesquisadores ${ }^{1}$. As ideias consideradas importantes e que deveriam ser incluídas no ensino são:

- O conhecimento científico baseia-se fortemente, mas não totalmente, na observação, na evidência experimental, em argumentos racionais e no ceticismo.

- As observações estão carregadas de teoria.

- A ciência é tentativa/erro.

- Não há uma maneira de fazer ciência e, portanto, não há passo a passo universal, um método científico que pode ser seguido.

- Leis e teorias possuem diferentes funções no domínio da ciência e, assim, as teorias não se tornam leis com provas adicionais.

- O progresso científico é caracterizado por uma concorrência entre teorias rivais. Diferentes cientistas podem interpretar os mesmos dados experimentais em mais de um caminho.

- O desenvolvimento de teorias científicas, às vezes, é embasado em fundamentos inconsistentes.

\footnotetext{
1 Embora essa ideia de consenso venha sendo criticada e debatida por alguns pesquisadores, pelo menos a partir de 2011 (ALLCHIN, 2013; ERDURAN; DAGHER, 2016), consideramos relevante apresentar a perspectiva de Níaz (2009), que analisou a falta de compreensão desses aspectos da natureza das ciências em pesquisas realizadas com professores.
} 
- Os cientistas são criativos e muitas vezes recorrem à imaginação e à especulação.

- As ideias científicas são afetadas por seu meio social e histórico.

Como justificativa à inclusão dessas ideias sobre a natureza da ciência no ensino, Níaz (2009) aponta que, para a maioria dos professores, em muitas partes do mundo, falta uma compreensão adequada de alguns ou de todos os diferentes aspectos sobre a natureza da ciência descritos anteriormente. Ainda, para este autor, foi surpresa verificar, em sua análise dos currículos de ciências e manuais escolares, uma forte inclinação deles para uma postura totalmente empírica e positivista.

Ao enfocar a natureza e a dinâmica da ciência, o professor estaria discutindo aspectos relativos ao campo da filosofia da ciência. Já ao abordar como o conhecimento científico é construído, ele estaria discutindo também a filosofia da ciência, mas, nesse caso, com um enfoque internalista, ou seja, estaria discutindo as metodologias de cada perspectiva filosófica. Em oposição, um enfoque externalista da construção do conhecimento científicos seria abordado por meio da história da ciência, onde seriam consideradas as influências dentro de um contexto mais amplo (social, econômico e político).

Para Praia e Cachapuz (1994), a imagem de ciência que os estudantes carregam depende, algumas vezes, do que lhes é proporcionado pelos seus professores de ciência. Assim, esses autores acham compreensível o crescente interesse da investigação educacional pelo ensino de ciência de um ponto de vista epistemológico. Segundo os autores, há atualmente evidências claras de que as concepções dos professores acerca da natureza da ciência, do conhecimento científico e do que é o método influenciam a forma de abordar um determinado conteúdo e, 
portanto, também influenciam a imagem da ciência transmitida ao aluno.

Portanto, levando em consideração essas discussões, apresentamos um episódio recente da história da ciência, visando ao aprendizado de conceitos científicos e de aspectos da natureza da ciência. Embora não seja muito usual tratar de fatos recentes na perspectiva histórica para o ensino, o episódio relacionado ao artigo publicado na revista Lancet (WAKEFIELD et al., 1998), que associava a vacina tríplice ao autismo, pode mobilizar diversos objetivos formativos no ensino de ciências. Consideramos que episódios recentes também são de grande valia em sala de aula para facilitar a aprendizagem significativa de conceitos científicos e discutir explicitamente uma concepção informada sobre a relação entre a ciência e a sociedade (ALLCHIN, 2013). Um dos aspectos positivos de se trabalhar com episódios contemporâneos é a facilidade com que podemos encontrar mais informações sobre ele. O episódio apresentado está envolvido em controvérsias atuais e pode favorecer a discussão de importantes aspectos da natureza da ciência em sala de aula, como o erro e a credibilidade científica.

\section{A construção do episódio histórico: vacina tríplice versus autismo}

Para Gil-Pérez (1993), no campo da didática de ciências, deve-se dar uma maior atenção às abordagens propostas da HFC no ensino de ciências e utilizá-las explicitamente na fundamentação de suas propostas. Contudo, segundo o autor, essa aproximação não significa fazer do aluno um pequeno cientista, 
como se refere à aprendizagem por descoberta, mas que a HFC assuma a função:

[...] de um autêntico fio condutor - mesmo que nem sempre explícito - na transformação do ensino de ciências. Um fio condutor que tem se mostrado frutífero inclusive através dos erros cometidos e que se vê reforçado tanto pelas orientações construtivistas como pelas implicações da epistemologia contemporânea no ensino. (GIL-PÉREZ, 1993, p. 11)

Portanto, a HFC não seria mais um aspecto ou outro conteúdo que o professor deveria levar em consideração em seu planejamento do ensino, mas sim ser o eixo que integra os conhecimentos científicos.

Apesar dessas orientações, têm-se observado em diferentes pesquisas que esse processo de inclusão não é algo simples de ser realizado. Muitas dificuldades são apontadas pelos professores em relação à inclusão da história da ciência $(\mathrm{HC})$ no ensino (MARTINS, 2007). As principais delas estão relacionadas à falta de conhecimento histórico específico, ao desconhecimento de fontes secundárias confiáveis, ausência de materiais adequados e estratégias pedagógicas, como também à visão inadequada desses professores sobre a natureza da ciência.

Porto (2010) aponta que uma das razões dessas dificuldades é a falta de discussões das diretrizes oficiais por parte dos professores. É importante que o professor compreenda qual visão sobre a HC que os documentos oficiais (propostas curriculares, parâmetros curriculares nacionais) orientam é adequada para o ensino e aprendizagem dos conhecimentos científicos.

Outro problema ligado à formação dos professores que Porto (2010) identifica diz respeito à questão da qualidade das fontes de informação sobre a HC. Embora atualmente o 
professor tenha acesso a diversas fontes de pesquisa, por meio de livros didáticos, revistas especializadas, internet, entre outros, o autor chama a atenção para qual história da ciência está vinculada por essas fontes, ou seja, em qual concepção historiográfica os autores desses materiais se basearam ao escrevê-los. De acordo com Forato, Martins e Pietrocola (2011, p. 35):

Qualquer narrativa da HC traz, implícita ou explicitamente, os valores, as crenças e as orientações metodológicas do seu autor. $\mathrm{O}$ relato histórico da criação de um conceito científico, ou de um debate entre teorias rivais, ou da realização de experimentos, por exemplo, carregam concepções sobre a natureza da ciência e sobre os processos da sua construção.

Portanto, faz-se necessário que o professor, ao ter acesso a materiais históricos (por exemplo, textos em livros didáticos), consiga identificar qual visão de ciência está vinculada a eles. Também é necessário que, na escolha do material, os professores problematizem a natureza da ciência dentro do episódio escolhido. Um modo de auxiliar a escolha é proposto por Allchin (2013, p. 44). De acordo com este autor, o professor pode fazer questões que o auxiliarão na definição e escolha do episódio a ser trabalhado, por exemplo: "Por que alguém deveria acreditar nisso?"; "Você consegue enxergar algum potencial viés ou erro?"; "Como você pode remediá-lo?". Também é possível fazer perguntas mais específicas, por exemplo: "Qual o efeito do erro para a saúde da população?".

Levando-se em consideração essas preocupações, acreditamos que o estudo de um determinado episódio histórico, construído a partir da orientação historiográfica atual, possa ser um material importante para o professor em sala de aula. 
A inclusão, no episódio, de debates e controvérsias pode facilitar a construção de uma visão mais crítica da ciência, mobilizando os aspectos pretendidos da natureza da ciência.

No exemplo que apresentamos, utilizamos o artigo original de Wakefield et al. (1998) e sua retratação (RETRACTION, 2010), assim como fontes secundárias que tratam diretamente do episódio, como o artigo de Lyall (2004) e a série de artigos do jornalista que denunciou o episódio, Brian Deer (2011a, 2011b, 2011c), ambos publicados no periódico científico britânico British Medical Journal. Nestes casos, há as citações e falas de pessoas diretamente envolvidas com o episódio. Também utilizamos artigos publicados pela imprensa internacional (CNN, BBC Brasil, Revista Época).

O que nos guiou para escolha do artigo - a além das qualidades citadas anteriormente de promover o debate de alguns aspectos da história e natureza da ciência - foi o fato de ser um problema atual, que atinge o cotidiano das pessoas. Além disso, a facilidade de encontrar dados de pesquisa e o grande impacto que essas discussões têm sobre a saúde da população.

\section{O episódio}

Em 1998 foi publicado na revista Lancet (WAKEFIELD et al., 1998) um artigo que associava a vacina tríplice - que protege contra sarampo, rubéola e caxumba - ao autismo. $\mathrm{O}$ artigo relatava que 12 crianças atendidas no Royal Free Hospital, localizado ao norte de Londres, apresentaram sintomas de uma nova síndrome, que relacionava autismo e a vacina tríplice.

A partir de sua publicação, o principal autor do trabaIho, o médico britânico Andrew Wakefield (1957-), usou seus 
dados para advogar contra o uso da vacina tríplice e a favor de vacinações individuais. Embora, quando publicado, tenha sido alvo de críticas por parte da comunidade científica, o trabalho teve grande repercussão na sociedade e levou ao surgimento de movimentos antivacinas que se tornaram fortes, principalmente nos Estados Unidos da América.

Após denúncias e um processo longo de investigação, o trabalho foi retratado, mesmo que 12 anos após a sua publicação (RETRACTION, 2010). As investigações mostraram que os dados foram forjados e alguns autores tinham sérios conflitos de interesse, o que levou a revista a retirar o artigo de seus arquivos. A retratação foi assinada por 10 dos 13 autores do trabaIho, e Wakefield foi um dos que não assinou. Além da retratação, a repercussão da fraude fez com que o pesquisador britânico perdesse sua licença médica. Porém, o estrago já tinha sido feito e até hoje, mesmo depois de mais de duas dezenas de trabalhos publicados mostrando que o trabalho de Wakefield é infundado, há consequências sérias à saúde pública devido a esse episódio.

$\mathrm{O}$ que se seguiu até que o trabalho fosse retratado foi uma diminuição no número de crianças vacinadas e o reaparecimento de casos de sarampo na América do Norte e Europa. O que os defensores da ideia de que a vacinação pode estar associada ao desenvolvimento de autismo não levam em conta é que outros trabalhos mostram resultados contrários. Além disso, as pessoas ignoram dados que mostram que indivíduos não protegidos contraem sarampo e podem sofrer danos neurológicos, auditivos e até mesmo ir a óbito.

Um artigo publicado na revista Science mostrou que a infecção pelo vírus do sarampo aumenta a predisposição das pessoas a outras doenças oportunistas por cerca de três anos após a infecção (MINA et al., 2015). Esse e outros exemplos 
encontrados na literatura médica levam a uma preocupação sobre o perigo de disseminação dessa doença devido a não vacinação de indivíduos dentro de uma população.

\section{A vacinação}

A vacinação é um método preventivo bem estabelecido na comunidade científica atual, que tem como princípio a manipulação da função do nosso sistema imunológico por meio da inoculação de agentes patogênicos atenuados ou de seus componentes. Em termos práticos, o objetivo da vacinação é o de produzir anticorpos específicos que protegerão o indivíduo em caso de infecção, fazendo com que não se desenvolva a doença ou que ela seja atenuada e, com isso, não traga prejuízos.

É interessante notar que a própria descrição da origem da vacinação é um episódio histórico rico para o uso da HFC no ensino. Infelizmente, a versão popular desse episódio é muito simplista, e fomenta uma visão ingênua sobre a natureza da ciência. Sua origem é comumente associada aos experimentos conduzidos por Edward Jenner (1749-1823) que demonstraram que a inoculação da varíola bovina protegia contra a varíola humana. Presente em grande número de livros textos, os experimentos realizados por Jenner contam a história de que mulheres as quais ordenhavam vacas que tinham sido infectadas por varíola bovina não contraíam varíola humana. Com base nessa observação, Jenner infectou um menino de oito anos - filho de uma empregada - com material retirado de uma pústula de uma vaca infectada. Tempos depois, ele inoculou o menino com a varíola humana e verificou que o menino não contraiu a doença. Esse episódio ficou amplamente conhecido e foi a razão da criação do termo "vacinação", cuja origem vem de vaccinius, vacca. 


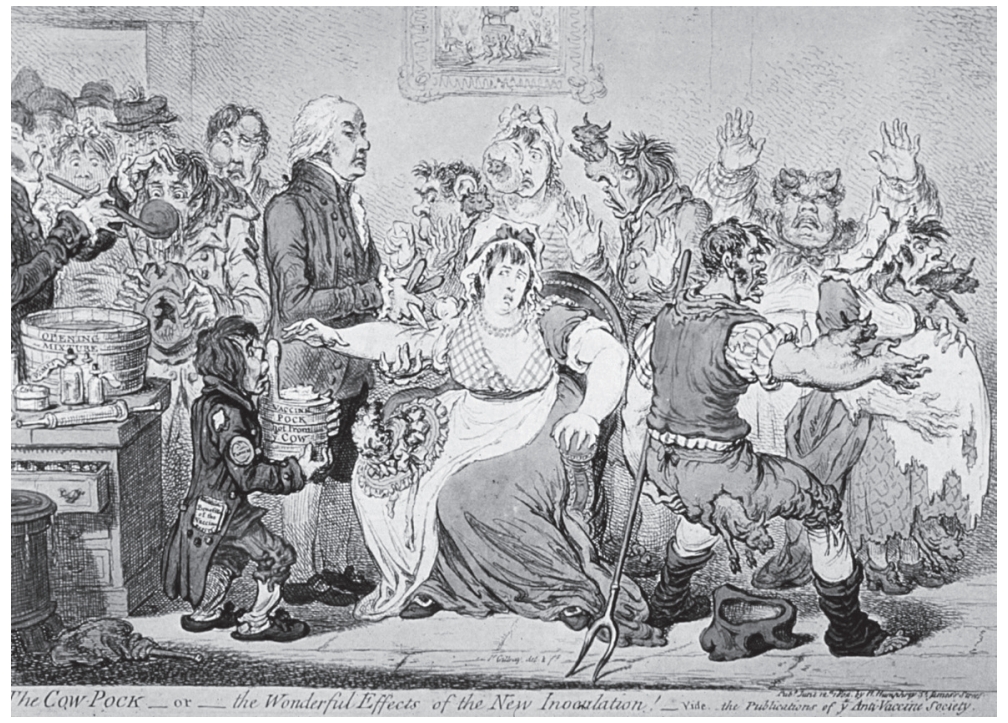

Figura 1 - Gravura de 1802, feita por James Gillray (1756-1815) mostrando as reações das pessoas à vacinação contra varíola. Embora alguns acreditem que a figura central é Edward Jenner (1749-1823) inoculando a senhora sentada, outros contestam essa afirmação. Também é possível ver partes de vacas saindo do corpo das pessoas, como referência aos oponentes à vacinação que disseminavam a ideia de que as pessoas adquiririam características das vacas.

Fonte: Wikimedia (http://www.wikimedia.org).

O que muitos livros não contam é que abordagens semeIhantes para prevenir a varíola já eram utilizadas desde o século $\mathrm{XV}$ por turcos e chineses. Antes mesmo de Jenner ter realizado seu experimento, Lady Mary Worley Montagu (1689-1762), esposa do embaixador britânico na Constantinopla, usou a técnica dos turcos em seus filhos. A técnica empregada por Lady Mary, que não era membro de uma comunidade das ciências, teve muita resistência na Inglaterra. Dentre os motivos de resistência, podemos supor a falta de credibilidade científica e o 
contexto sociocultural, uma mulher não "cientista" aplicando conhecimentos provenientes do oriente na Europa Ocidental do século XVIII (REMILLARD, 2007).

O caso que apresentamos para discussão também se relaciona com a credibilidade científica. No entanto, ao contrário do que aconteceu com Lady Mary, cuja falta de credibilidade fez com que o método usado por ela fosse amplamente contestado, no caso de Wakefield, foi justamente a credibilidade que proporcionou a ampla aceitação do seu trabalho.

Ao publicar seus resultados na respeitada revista Lancet, Wakefield, teve seu trabalho protegido pelo "manto" da ciência. A revista britânica, fundada em 1823, é reconhecida pelo seu alto impacto e por publicar trabalhos de excelência científica. $\mathrm{Na}$ época da publicação do artigo de Wakefield, a revista contava com 175 anos de experiência e reconhecimento.

Exemplo da credibilidade obtida pela publicação pode ser dado pela fala da então presidente da Autism Science Foundation e mãe de uma criança com autismo, Alison Singer, à rede de televisão estadunidense CNN em fevereiro de 2010. $\mathrm{Na}$ época, em meio a uma reportagem que expunha a retração do trabalho, Singer comentou que os motivos que levaram as pessoas a não questionarem os resultados apresentados foram devido ao fato de que "[...] a estória se tronou crível, pois foi publicada na Lancet", e complementa: "foi na Lancet, e nós confiamos nesses periódicos médicos" (PARK, 2010).

A reação de Alison é esperada na nossa cultura, em que há pouco questionamento sobre o que a ciência produz. Mas, o que perguntamos é: por que ainda há pessoas que acreditam nos resultados de Wakefield e ignoram outros que contradizem os resultados? Alguns pontos podem ser levantados para essa discussão. Um deles se deve ao fato de que o texto do artigo não é 
categórico na afirmação que realmente há uma associação entre a vacina tríplice e o desenvolvimento do autismo. Embora proposto no texto do artigo, o impacto foi realmente causado mais pela fala de Wakefield durante uma entrevista coletiva após a publicação do que pelo texto do artigo em si, como sugere Richard Horton, editor da Lancet na época da publicação (LYALL, 2004, p. 528).

Outro ponto importante é a forma como as pessoas buscam informações atualmente. Não é difícil encontrar artigos como o da BBC Brasil (2002), que alertam sobre os riscos da vacina tríplice e utilizam o artigo de Wakefield como argumento favorável ao risco. No entanto, reportagens desse tipo não fazem qualquer menção ao fato de ele ter sido retratado. De certa forma, meios de comunicação também têm ou não credibilidade e é fato que emissora britânica BBC é reconhecida pela credibilidade na informação. Nesse caso em particular, nota-se que o artigo recebeu sua última atualização em março de 2004, porém devemos lembrar que a retratação oficial só ocorreu em 2010.

Além disso, também existem crenças pessoais que são difíceis de se rebater, como o caso da porta voz do Talk About Curing Autism, Rebecca Estepp, que afirma à CNN que "[...] o $\mathrm{GMC}^{2}$ pode dizer quaisquer coisas que eles queiram pelo resto de sua existência, mas eu sei que meu filho melhorou por causa do Dr. Wakefield".

Além da credibilidade científica, outro ponto importante que pode ser trabalhado com este episódio refere-se ao fato de que a autoridade da ciência vem da sua capacidade de se autocorrigir. Porém, essa correção pode não acontecer ou, então, acontecer após um longo período. Nesse sentido, Douglas Allchin (2015, p. 20) pontua que:

${ }^{2}$ General Medical Council, organização britânica independente que ajuda a proteger os pacientes e melhorar o ensino de medicina. 
Os cientistas examinam o trabalho uns dos outros ceticamente, tentam repetir descobertas importantes e por isso expõem erros latentes. Assim, embora a ciência seja tentativa, parece também haver um sistema para corrigir quaisquer erros que apareçam. Isso explica poderosamente e justifica a autoridade da ciência. Autocorreção, portanto, serve em geral emblematicamente para promover a ciência como uma forma superior de conhecimento. Mas erros podem ocorrer e ocorrem. Alguns erros permanecem sem correção por longos períodos.

No episódio apresentado, o "erro" - leia-se fraude - foi denunciado pelo jornalista investigativo Brian Deer em 2011, um ano após a publicação da retratação (DEER, 2011a, 2011b, 2011c). Esse tempo entre publicação, denúncia e retratação foi mais que suficiente para que a informação fosse espalhada e seus efeitos observados. Ainda que pudéssemos sugerir que a presença do mecanismo de autocorreção tenha acontecido, neste caso, ela não aconteceu a contento, o que reforça a "Teoria do Mito da Autocorreção", como proposto por Allchin (2015).

\section{Considerações finais}

Neste capítulo, discutimos o episódio histórico recente sobre a relação entre a vacinação e o estabelecimento do autismo. O episódio permite trabalhar, principalmente, dois conceitos importantes sobre a natureza da ciência: o da credibilidade científica e o do mito da autocorreção, como proposto por Allchin (2015).

Ao somar a esse episódio o nosso contexto social atual, com base na busca aleatória de informação sem embasamento apropriado, mostramos a necessidade de repensarmos a 
formação de jovens durante o ensino básico, principalmente no que se refere ao ensino de história e natureza das ciências com via a formar indivíduos mais bem informados para tornar decisões baseadas em dados.

Por fim, queríamos esclarecer que, embora o trabalho de Wakefield et al. (1998) seja falho em vários aspectos, ele não deve ser usado como validação de uma teoria oposta: a de que a vacinação não traz riscos. Afinal, o método de aquisição de proteção imunológica contra agentes patógenos não é livre de riscos. Visto que, por exemplo, a vacina oral que imuniza para poliomielite, feita com o vírus atenuado, em raras ocasiões pode causar paralisia e, em outros também raros casos, choque anafilático. Porém, o risco é baixíssimo quando comparado com os benefícios da vacinação, principalmente quando analisamos a vacinação como um contrato social, ou seja, ato que necessita que cada membro da sociedade faça sua parte.

Os riscos da quebra desse contrato acontecem quando verificamos a existência de pessoas que não se vacinam no meio de um grupo vacinado. Nesse caso, observamos o surgimento de uma falsa sensação de proteção, visto que as pessoas vacinadas não transmitirão a doença para um indivíduo não vacinado. É essa falsa sensação de proteção, juntamente com os problemas apresentados neste capítulo, que levam algumas pessoas a defenderem a não vacinação e, dessa forma, a comprometerem o efeito protetor das vacinas.

\section{Referências}

ALLCHIN, Douglas, Teaching the Nature of Science: Perspectives \& Resources. Saint Paul, MN: SHiPS Educational Press, 2013. 
. Correcting the "self-correcting" mythos of Science. Filosofia e História da Biologia, v. 10, n. 1, p. 19-35, 2015.

BBC BRASIL. Cientistas alertam sobre novos riscos da vacina tríplice viral. 27 jun. 2002. Saúde \& Tecnologia. Disponível em: <http://www.bbc.com/portuguese/ciencia/020627_mmrmtc. shtml>. Acesso em: 5 jul. 2016.

CACHAPUZ, António Francisco Carrelhas; PRAIA, João Felix; JORGE, Manuela. Ciência, Educação em Ciência e Ensino das Ciências. Lisboa: Ministério da Educação, 2002.

DEER, Brian. How the case against the MMR vaccine was fixed. The British Medical Journal, v. 342, p. c5347, 2011a.

. How the vaccine crisis was meant to make money. The British Medical Journal, v. 342, p. c5258, 2011 b.

. The Lancet's two days to bury bad news. The British Medical Journal, v. 342, p. c7001, 2011c.

ERDURAN, Sibel; DAGHER, Zoubeida. Reconceptualizing the Nature of Science for Science. Science \& Education, v. 25, n. 1, p. 147-164, 2016.

FORATO, Thaís Cyrino de Mello; MARTINS, Roberto de Andrade; PIETROCOLA, Maurício. Historiografia e natureza da ciência na sala de aula. Caderno Brasileiro de Ensino de Física, v. 28, n. 1, p. 27-59, abr. 2011.

GIL-PÉREZ, Daniel. Contribución de la historia y la filosofía de las ciencias al desarrollo de um modelo de enseñanza/aprendizaje como investigación. Enseñanza de las Ciencias, v. 11, n. 2, p. 197-212, 1993. 
GONZÁLEZ, Antonio Moreno M. Historia de la ciencia: una posible contribución a la formación de los profesores. In: BLANCO NIETO, Lorenzo J.; JIMÉNES, Vicente Mellado (Coord.). La formacion del profesorado de ciencias y matematicas en España y Portugal. Badajóz: Universidad de Extremadura, 1995. p. 345-360.

LYALL, Joanna, Editor in the eye of a storm. The British Medical Journal, v. 328, n. 7438, p. 528, 2004.

MARTINS, André Ferrer Pinto. História e filosofia da ciência no ensino: há muitas pedras nesse caminho. Caderno Brasileiro de Ensino de Física, v. 24, n. 1, p. 112-131, 2007.

MINA, Michael J.; METCALF, Jéssica; SWART, Rik L. de; OSTERHAUS, Albert; GRENFELL, Bryan T. Long-term measles-induced immunomodulation increases overall childhood infectious disease mortality. Science, v. 348, n. 6235, p. 694-699, 2015.

NÍAZ, Mansoor. Progressive transitions in chemistry teachers' understanding of nature of science based on historical controversies. Science \& Education, v. 18, n. 1, p. 43-65, 2009.

PARK, Madison. Medical journal retracts study linking autism to vaccine. feb. 2010. CNN. Disponível em: <http://edition. cnn.com/2010/HEALTH/02/02/lancet.retraction.autism/index. html?hpt=T2>. Acesso em: 5 jul. 2016.

PORTO, Paulo Alves. História e Filosofia da Ciência no Ensino de Química: em busca dos objetivos educacionais da atualidade. In: SANTOS, Wildson Luiz Pereira dos; MALDANER, Otávio Aloísio (Org.). Ensino de Química em Foco. Ijuí: Editora Unijuí, 2010. p. $159-180$. 
PRAIA, João Felix; CACHAPUZ, António Francisco Carrelhas. Un análisis de las concepciones acerca de la naturaleza del conocimiento científico de los profesores portugueses de la enseñanza secundaria. Enseñanza de las Ciencias, v. 12, n. 3, p. 350-354, 1994.

REMILLARD, Erika. Lady Mary Wortley Montagu and smallpox inoculation in 18th-century England. Minneapolis, MN: SHiPS Resource Center, 2007. Disponível em: http://www. shipseducation.net/modules/biol/smallpox.htm>. Acesso em: 28 set abr. 2016.

RETRACTION - Ileal-lymphoid-nodular hyperplasia, non-specific colitis, and pervasive developmental disorder in children. The Lancet, v. 375, n. 9713, p. 445, 2010. Disponível em: http://www.thelancet.com/journals/lancet/article/PIIS01406736(10)60175-4/abstract. Acesso em: 18 out. 2016

WAKEFIELD, Andrew Jeremy; MURCH, Simon. H.; ANTHONY Andrew.; LINNELL, John.; CASSON, D. M.; MALIK, M.; BERELOWITZ, Mark.; DHILLON, A. P., THOMSON, M. A.; HARVEY, P.; VALENTINE, A.; DAVIES, S. E.; WALKER-SMITH, John A. Retracted: Ileal-lymphoid-nodular hyperplasia, nonspecific colitis, and pervasive developmental disorder in children, The Lancet, v. 351, n. 9103, p. 637-641, 1998. Disponível em: http://www.thelancet.com/journals/lancet/article/PIIS01406736(97)11096-0/fulltext. Acesso em: 18 out. 2016.

WIKIMEDIA. The cow Pock. 2016. Disponível em: <https:// upload.wikimedia.org/wikipedia/commons/thumb/d/d6/The cow_pock.jpg/800px-The_cow_pock.jpg>. Acesso em: 15 abr. 2016. 